\title{
Vehicular Emissions and Its Implications on the Health of Traders: A Case Study of Traders in La Nkwantanang Municipality in Ghana
}

\author{
Doris Dushie $^{1}$, Ama P. Fenny ${ }^{2} \&$ Aba O. Crentsil ${ }^{3}$ \\ ${ }^{1}$ Environmental Protection Agency, Accra, Ghana \\ ${ }^{2}$ Economics Division, Institute of Statistical, Social and Economic Research (ISSER), University of Ghana, \\ Accra, Ghana \\ ${ }^{3}$ Social Division, Institute of Statistical, Social and Economic Research (ISSER), University of Ghana, Accra, \\ Ghana \\ Correspondence: Ama Pokuaa Fenny, Economics Division, Institute of Statistical, Social and Economic Research \\ (ISSER), University of Ghana, P.O. Box LG 74, Accra, Ghana. Tel: 233-2433-43855; 233-261-563-405. E-mail : \\ amafenny@yahoo.co.uk; apfenny@ug.edu.gh
}

Received: August 23, 2017

doi:10.5539/jsd.v10n6p241
Accepted: November 1, 2017

Online Published: November 29, 2017

URL: https://doi.org/10.5539/jsd.v10n6p241

\begin{abstract}
The study was based on the recognition that although the health conditions of the human population is vital to sustainable living and productivity, some studies have found that road traffic emissions continue to give rise to infectious and chronic diseases. As a result, the study aimed at assessing the implications of vehicle emissions on the health of traders in Madina in the La Nkwantanang Municipality of Ghana where road traffic is very congested and traders are directly exposed to vehicle emissions. To achieve this objective, 300 traders, made up of 150 traders within a distance of 50 meters and 150 traders within a distance beyond 50 meters of the main road were purposively selected to participate in the survey. Data obtained was analysed using descriptive and inferential statistics. The findings show that although a significant proportion of the respondents had good knowledge about the health consequences of their exposure to emissions, they were reluctant to relocate due to their inability to afford a different location and scarcity of urban space. More importantly, frequent coughing, nausea, poor visibility and difficulty in breathing were among the major self-reported health outcomes. The study also found statistically significant difference in the distribution of self-reported health outcomes by distance of respondents from source of vehicle emission. Also, years spent in the occupation and average daily work hours per week were among factors that related significantly with reported cases of respiratory diseases by respondents.
\end{abstract}

Keywords: vehicular emissions, health, traders, survey, Ghana

\section{Introduction}

The health of the world's population is of crucial importance and this underpins every development agenda across the globe (WHO, 2002). It forms the basis for assessing progress on human development and growth (Cohen, 2010; Bloom, Canning \& Sevilla 2004; Spence \& Lewis, 2009). Regardless of the importance of health to human progress, empirical evidence shows that a number of people worldwide suffer from pollution-related illnesses, which include asthma, chronic obstructive pulmonary diseases (COPD), cardiovascular diseases, and lung cancer (Wargo, Wargo, \& Alderman, 2006; Alim et al. 2014). According to the International Energy Agency (IEA), about 18,000 people worldwide die each day from prolong exposure to air pollution (IEA, 2016). In Europe and the United States of America, strict compliance to environmental regulatory instruments account for the minimal risk of exposure to air pollution and its attendant health implications (WHO, 2000). According to the IEA (2016: 125), efforts related to air pollution control in the United States of America date back to early 1960s and have resulted in significant reduction in air pollution by 70 percent between 1970 to date. Similar efforts in Europe, is believed to have led to a reduction in emission of sulfur dioxide $\left(\mathrm{SO}_{2}\right)$ concentration in the air by 90 percent between 1990 and 2013 while total particulate matter $\left(\mathrm{PM}_{2.5}\right)$ concentration dropped by more than 50 percent over the same period (IEA, 2016: 153). Dimitriou, and Christidou (2011) linked the fundamental drivers of global air pollution to both natural and anthropogenic factors. The latter, according to them, accounts for more than 90 percent of air pollution worldwide today. Further studies point to emissions from energy consumption 
sources including vehicular emissions as being responsible for more than 40 percent of air pollution in developing countries and as second to combustions and industrial air pollution (UNEP, 2014; Bell et al., 2006; European Environmental Agency, 2006).

In Southern Asia and Latin America on the other hand, studies point to weak pollution regulatory instruments as the main reason accounting for the increase in respiratory diseases and deaths caused by exposure to air pollution (Cifuentes et al., 2005; Kampa, \& Castanas, 2008). According to the IEA (2016), about 70,000 premature deaths were recorded in Indonesia as a result of exposure to outdoor air pollution. Similar observation by the United Nations Environment Programme (UNEP) (2014), indicates that 7 out of every 10 people in Southern Asia suffer from severe risk of exposure to air pollution. The study concludes that about 83 percent of all pollution related deaths in India are caused by air pollution. The situation is even worse in cities such as Mexico, Santiago, Sao Paolo, China and India where growth in industrialisation coupled with little attention to environmental safety combine as a negative sum-game-effect responsible for compromising the health of urban residents (Bell et al. 2006; Ribeiro, Regina \& Cardoso, 2003; Rohde \& Muller, 2015). In India and China for instance, it is estimated that less than one percent of the population live in areas meeting WHO air quality standards. ${ }^{1}$

In Africa, the challenge with regards to risk of exposure to air pollution is quite severe and extensive. According to Omole and Ndambuki (2014), rapid population expansion, increase in the demand for fossil fuel consumption and uncontrolled extraction and industrial activities are the major causes of air pollution in Africa. However, a report by UNEP (2014), shows that in urban areas vehicular emissions remain the major cause of air pollution. Between 1990 and 2013 it was estimated that the cost of premature deaths induced by air pollution in Africa rose by 36 percent to about 250,000 (OECD, 2016). This shows how extensive and dangerous air pollution is causing harm to the human population. Ghana exhibits similar trends, worsened further by growing indiscipline and negligence towards environmental health and safety compliance (EPA, 2015). This is demonstrated in the increasing trend in total greenhouse gas (GHG) emissions from various sources including vehicular emissions (ISSER, 2013). The situation is aggravated by the increasing importation of secondhand vehicles for use in densely populated urban areas. Therefore, making exposure to vehicular emissions quite severe and extensive. By March 2012, an estimated 1.5 million vehicles were registered in Ghana, out of which Accra and Tema, both densely populated areas accounted for about 60 percent of registered cars (Tetteh-Addison, 2012). Most of these vehicles are energy inefficient and therefore responsible for emitting dangerous gases and heat that affect the health of the general population. This may explain the rise in respiratory infections in Ghana (World Health Organisation, 2015). Similar observation by the Ghana Centers for Disease Control and Prevention shows that respiratory infections was the second cause of death after malaria and constituted 9 percent of the total deaths recorded in 2010 .

The choice of this study is premised on the need to contribute to the broader discussion on how people perceive specific diseases and their knowledge and practices towards achieving healthy lives and well-being. The outcome of the study will provide knowledge, attitude and practices of traders in Madina with regards emission related health outcomes. This will provide information to support communication strategies to educate the public on emission related health hazards. The choice of Madina as the spatial scope of the study is justified by two reasons. First, Madina best exhibits the problem of intense vehicular traffic, emissions and exposure. For instance, Odame (2015) indicated that as of 2014, an estimate 1002 vehicles ply the Madina traffic light and Rawlings Circle road every hour. This coupled with the population density of Madina including traders make it suitable for the study.

Utlimately, this study seeks to assess the health implications associated with vehicular emissions among traders in Madina and is guided by the following specific objectives: (1) to ascertain the perception of disease exposure among traders; (2) to identify the effects of emissions on self-reported health among traders; and (3) to determine the risk factors associated with illness due to vehicle emissions.

\subsection{Perspectives on Vehicular Emissions and Health}

Vehicular emissions constitute one of the major sources of global air pollution and has several health related implications on the human population (Cohen et al. 2004). Studies (Pandian et al. 2008; Beydoun \& Guldmann, 2006) show that three possible interrelated set of things account for different levels of vehicular emissions. The first being that, an increase in the manufacturing of different models of vehicles gives rise to different levels of emissions, particularly as a result of differences in innovation and technology. Beydoun and Guldmann (2006)

\footnotetext{
1 For more statistics see Global Burden of air pollution, Deaths from air pollution in 2013 report. Avaliable at: http://www.healthdata.org/sites/default/files/files/infographics/Infographic_AAAS_Air-pollution_2016.pdf
} 
argue that as vehicles age they become more energy inefficient and therefore consumes more fuel and emit more dangerous gasses which in turn increase the health burden of the population. Also, traffic-generated plume from vehicles includes particulate matter $(\mathrm{PM})$ with a gaseous pollutant mixture of nitrogen oxides $\left(\mathrm{NO}, \mathrm{NO}_{2}\right)$, carbon monoxide (CO) and multiple volatile organic compounds (e.g., benzene, ethene, ethylene and toluene). These components are associated with a range of short-term and long-term health effects; such as childhood asthma incidences (Khreis et al 2016), allergic diseases in Children (Seon-Ju Yi et al 2017), cardiovascular disease incidence (Cesaroni et al., 2014), cardiovascular mortality and morbidity (Héroux et al., 2015), respiratory infections (MacIntyre et al., 2014) and respiratory mortality and morbidity (Health Effects Institute, 2010; Héroux et al., 2015; Kurt et al., 2016). Secondly, Pandian et al. (2008) note that high vehicular traffic is associated with high vehicular emission. This means that proximity to high vehicular traffic constitutes a risk factor to respiratory diseases. The third contributory factor, is the lack of monitoring to ensure effective implementation of air quality standards (Zachariadis et al. 2001; Pandian et al. 2008).

The large numbers of secondhand vehicles in use in Africa, combined with the poor quality of petroleum products exposes many to pollution related diseases. For instance, a report by Guenlat et al. (2016) attributes the excessive concentration of toxic substances in diesel and petrol fuel in Africa as a lead cause of premature death. The authors indicated further that based on their laboratory sample test, the Sulphur concentration in petroleum products used by vehicles in Africa is 150 times higher than the acceptable European standard of $10 \mathrm{ppm}$ and as a result responsible for the high levels of outdoor air pollution. The IEA (2016) adds that if effective regulation of fuel standard could be checked to reduce Sulphur concentration in diesel and petrol consumed in Africa, the continent could prevent 25,000 and 100,000 premature deaths by 2030 and 2050 respectively. Also of significant concern is the fact that the premature death burden of exposure to air pollution is also highly gendered with women being the most susceptible, except when controlled for tobacco smoking which men generally dominate (WHO, 2014).

\subsection{Interface between Risk Factors and Emission Related Diseases}

Empirical studies have documented several risk factors associated with illnesses caused by exposure to air pollution in general. Variations in the risks and illnesses have been linked to the longevity of exposure, the health history of the individual as well as the intensity and type and level of concentration of the pollutant (Chauhan \& Johnston, 2003; Brauer et al. 2002; Schwartz, 2004). For instance, Brauer et al. (2002), studied traffic air pollution and its effect on respiratory diseases in the Netherlands using multiple logistic regression to estimate risk of infection. They used two different concentration levels of pollutants $\left(\mathrm{PM}_{2.5}=\right.$ particulate matter less than $2.5 \mu \mathrm{m}$ in aerodynamic diameter; $\mathrm{NO}_{2}=$ nitrogen dioxide) to determine the risk of infection based on reported evidence of wheeze, dry cough, doctor-diagnosed bronchitis, itchy rash, and diagnosed flu/severe cold. Consequentially, they found strong association between the pollutants and increased incidence of respiratory infections. The findings also corroborate with other studies (Venn et al. 2001; Hwang et al., 2005) and therefore indicate that $\mathrm{NO}_{2}$ and $\mathrm{PM}_{2.5}$ concentrations in the air as result of vehicular emissions poses severe risk to human health. Neiderud (2015) also note that urban population density account for the risk of transmission of respiratory infection. Thus, one could easily be infected by respiratory virus and bacteria through contact.

Alirol et al. (2010) note that an estimated population density of beyond 30,000 persons per $\mathrm{km}^{2}$ severely contribute to the transmission of respiratory diseases in most cities in Asia, mainly as a result of competition for limited airspace and frequent human contact. This means that infections caused by exposure to vehicular emissions could be easily transmitted from person to person in densely populated areas of intense vehicular traffic, raising a deep concern for public health. Drawing from other related literature, Hwang et al. (2005) identified raised blood pressure, impaired pulmonary function and allergic reactions as common morbidity outcomes associated with illnesses caused by exposure to air pollution in general. Thus, for those exposed to prolong vehicular emissions there is high tendency of allergic reactions and impaired pulmonary functions which often vary depending on the individual's immune system.

The variation and severity of risks associated with illnesses caused by exposure to air pollution demands effective interventions, explaining why Europe has adopted several mechanism including early warning systems, medical information systems, public health intelligence systems (Semenza et al., 2016). These mechanisms have enabled the tracking of 21 different infectious disease threat events (IDTEs) directly linked to outdoor air pollution. The interwoven relationship between vehicular emissions and human health, particularly the spread of respiratory diseases is drawn from different empirical studies (Ribeiro, 1999; US Environmental Protection Agency 2009; Apte et al. 2012; Zuraimi et al., 2011). From a more scientific perspective, Apte et al. (2012) provides an elaborate parameter for explaining human exposure to vehicular emissions. According to the authors, the inhaled fraction of emission can be measured on a scale of between 0 to 1 , where a dose of $10 \mathrm{ppm}$ will 
transcend into half a million grams of the emitted compound or gas.

\subsection{Ghana's Road Transport and the Issues of Emissions}

Ghana faces a severe health and environmental threats as a result of emissions from various sectors including road transportation. The EPA (2015), estimated the total greenhouse gas (GHGs) emissions from Ghana at 33.66 million tons of $\mathrm{CO}_{2}$ equivalent $\left(\mathrm{MtCO}_{2} \mathrm{e}\right)$ in 2012. These emissions, according to the United Nations Framework Convention on Climate Change (UNFCCC) (2008) consist of dangerous gasses that contribute ozone depletion and excess concentration of nitrogen and sulphur dioxide which account for the numerous spread of environmental diseases such as respiratory infections. Between 2010 and 2012, the transportation sector remained the third largest contributor to Ghana's total GHGs emission, increasing from $4.8 \mathrm{MtCO}_{2}$ to $6.45 \mathrm{MtCO}_{2}$ respectively. For instance, in 2013, it was estimated that total vehicle registration in Ghana rose by 23 percent above the previous year figure ${ }^{2}$. Tetteh-Addison (2012) noted that about 83 percent of the vehicles imported into Ghana are secondhand cars.

\subsection{Overview of Respiratory Disease Profile of Ghana}

The Ghana Demographic and Health survey (GDHS) report of 2014 indicates that non-communicable diseases are leading cause of deaths among children and adults in Ghana. As of 2002, an estimated 1,295 out of 3,085 people with severe respiratory tract infection died at the Korle Bu Teaching Hospital alone. ${ }^{3}$ In 2012, the World Health Organisation (WHO) also identified lower respiratory infections as contributing to about 11 percent $(10.7 \%)$ of top ten causes of death in Ghana. This, according to WHO, account for approximately 22.4 deaths per every 1000 of the population. Comparatively, the death burden of lower respiratory infection in Ghana is higher than South Africa, United States of America and the United Kingdom but slightly lower than other developing countries of Africa including Benin, Togo and Nigeria (See Figure 1). Similar trends were observed for the percentage distribution of deaths caused by ARI among children under age 5 years in 2012/2013. This trend indicates the need for greater attention to be paid to reducing the number of deaths caused by LRI and ARI in Ghana.

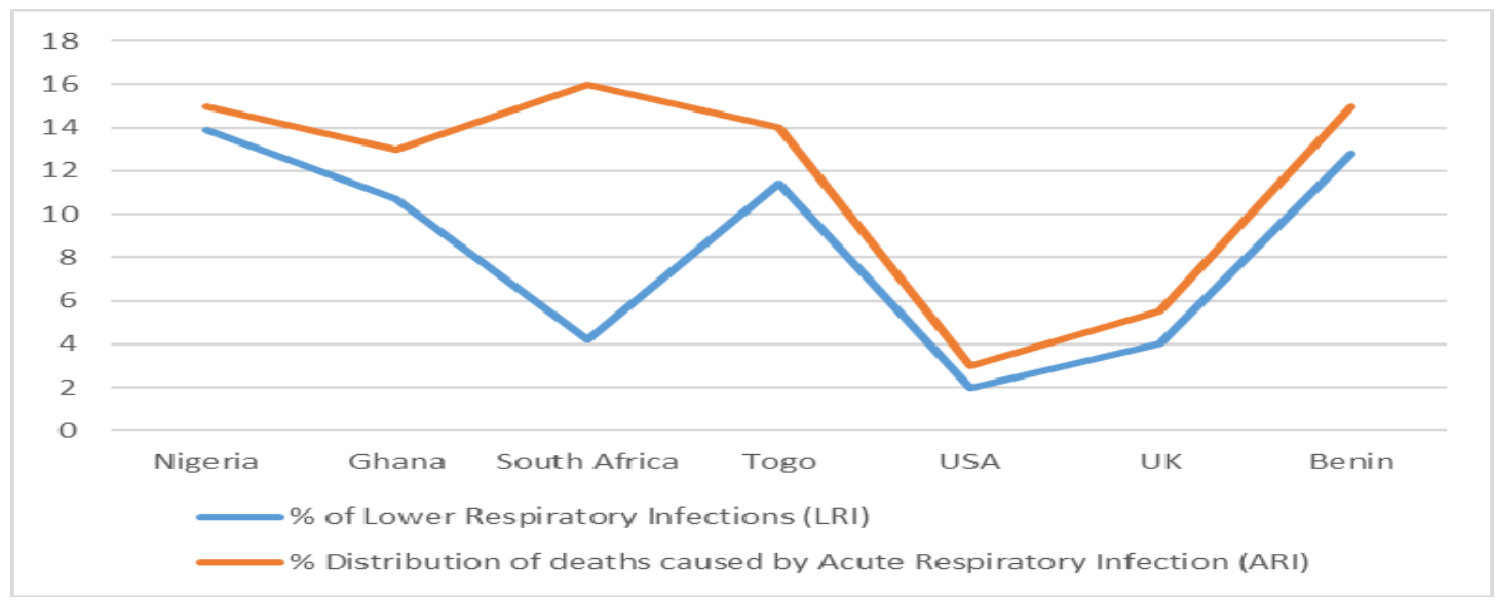

Figure 1. Death resulting from respiratory infections by country, 2012/2013

Source: Compiled by Author based on WHO Country Statistics ${ }^{4}$

\section{Methodology}

A mix method study design was adopted for the study. This method has been particularly suitable for social science research because it reduces biases associated solely with qualitative and quantitative studies (Kumekpor, 2002; Neuman, 2010). The population of the study refers to all traders operating within 50-meter radius from both sides of the major roads in Madina. These include those operating as hawkers and in shops within 50 and 100 -meter radius who are on daily basis exposed to intense vehicular emissions by virtue of their livelihood activity. In order to measure the perception of disease exposure among traders, the knowledge, attitude and

\footnotetext{
${ }^{2}$ The number of cars in Ghana increases by $23 \%$. Available at: https://www.newsghana.com.gh/the-number-of-cars-in-ghana-increases-by-23/ Respiratory tract infection major cause of death in Ghana Available at: http://www.ghanaweb.com/GhanaHomePage/NewsArchive/Respiratory-Tract-Infections-major-cause-of-death-in-Ghana-59689

${ }^{4}$ WHO country statistics. Available at: http://www.who.int/gho/countries/ben.pdf
} 
practice (KAP) survey designed by the World Health Organisation (2008) was employed. Also, a modified version of the European Community Respiratory Health Survey (ECRHS) instrument used by Alim et al. (2014) was adapted to measure the effect of traffic emissions on self-reported health among traders. In order to measure the risk factors associated with illness due to vehicular emissions, respondents were asked to state their perception of the health risks they faced daily during their trading activities.

\subsection{Model Specification for Determinants of Risk Factors}

Risk factors for respiratory infections $(R I)$ was coded as a dichotomous variable to describe whether or not respondents had experienced health effects as result of their exposure to vehicle emission (Yes $=1$ and $0=$ otherwise). This variable was treated as a dependent variable in a logistic regression estimate of the relative risk of $R I$ among respondents. The independent variables considered in the model include age of respondents (Age), average daily hours spent at their designated point of trade $(H S D)$, years spent in the occupation at the designated point of trade $(Y S D)$, their educational level (EDU), gender (Gen) and distance from highway pollution (Disp). Thus, in exception of educational level and gender the remaining four independent variables will be represented as continuous variables. The logistic regression equation is therefore modeled as:

$$
\begin{aligned}
\operatorname{Pr}(\mathrm{RI}=1 / \mathrm{X}=\mathrm{Age}, \mathrm{HSD}, \mathrm{YSD}, \mathrm{EDU}, \mathrm{Gen}, \mathrm{Disp})=\underset{ }{=}\left(\beta_{0}+\beta_{1} \text { Age }+\beta_{2} H S D+\beta_{3} Y S D+\beta_{4} E D U+\beta_{5} G e n+\beta_{6}\right. \\
\text { Disp }) .
\end{aligned}
$$

Where aside the variables specified earlier,

$\beta_{0}=$ the model intercept; $\mathrm{F}=$ the cumulative logistic distribution function

Although the parameters of the model did not provide a good explanation on the effect of the independent variables on risk of respiratory infection among respondents, the marginal effect provided probability estimate on relative risk of respiratory infection among respondents. This model was preferable because the slope of the coefficient takes into consideration any form of changes in the explanatory variables, given also that the dependent variable is a dummy variable.

\section{Results}

\subsection{Descriptive Statistics of Respondents' Background}

Out of the total observation of 300 respondents, 79 of them representing about 26 percent $(26.3 \%)$ were accompanied by other people to their place of work at the time of the survey. The proportion of the total female respondents with accompaniers were about 40 percent (39.6\%) compared with about one percent (0.9) for their male counterparts. The mean age was 31 years and the minimum and maximum ages were 19 and 52 years respectively. Male respondents constituted 34.3 percent and thus given a male to female ratio of approximately 3:7 respectively. The proportion of the sample who smoke at the time of the survey was about 23 percent representing 68 out of the total 300 sample. It was also revealed that those who smoke were all males. Years spent by respondents as traders was also examined. The data revealed that on the average each respondent has spent about 4 years in their current occupation as traders. Further analysis of the data show that on the average respondents work about 6 days in a week. More importantly, cost of treatment for reported illness in the last six months by respondents ranged between GH $\not 30.00$ to GH $\phi 160.00$. Only 60 percent of the respondents representing 180 out of the 300 sample indicated that they had valid national health insurance card.

In terms of education, 82 percent of the respondents said they have either basic, secondary or technical education while the remaining had none. With regards to religious affiliation, about 35 percent (34.7\%) of the respondents were Christians while the remaining were Muslims (17.3\%), Traditionalists (15.3), and no religion (32.7\%). More so, those who were married at the time of the survey were 57.3 percent while those who were never married and those in consensual union constituted 12.7 and 30 percent respectively (Table 1).

Table 1. Descriptive statistics

\begin{tabular}{lcccc}
\hline Variables & Mean (Obs.) & Std. Dev. & Min & Max \\
\hline Age in completed years & $31(300)$ & 8.1421 & 19 & 52 \\
Years of being a trader & $4.2(300)$ & 2.1296 & 1 & 17 \\
Working days per week & $5.5(300)$ & 0.89 & 4 & 7 \\
Years diagnosed of chronic condition & $2.3(232)$ & 1.4947 & 1 & 5 \\
Number of times reported ill in 6 months & $2.2(125)$ & 0.7 & 1 & 3 \\
Average treatment expenditure & $65(115)$ & 26.53 & 30 & 160 \\
\hline
\end{tabular}




\begin{tabular}{|c|c|c|}
\hline & Frequency & Percentages \\
\hline \multicolumn{3}{|l|}{ Gender } \\
\hline Male & 103 & 34.3 \\
\hline Female & 197 & 65.7 \\
\hline Total & 300 & 100.0 \\
\hline Smoking & - & - \\
\hline Yes & 68 & 22.7 \\
\hline No & 232 & 77.3 \\
\hline Total & 300 & 100.0 \\
\hline Religion & - & - \\
\hline Christian & 104 & 34.7 \\
\hline Muslim & 52 & 17.3 \\
\hline Traditional & 46 & 15.3 \\
\hline None & 98 & 32.7 \\
\hline Total & 300 & 100.0 \\
\hline Health insurance & - & - \\
\hline Yes & 180 & 60.0 \\
\hline No & 120 & 40.0 \\
\hline Total & 300 & 100.0 \\
\hline Reported ill in last six months & - & - \\
\hline Yes & 124 & 41.3 \\
\hline No & 176 & 58.7 \\
\hline Total & 300 & 100.0 \\
\hline Diagnosed of chronic condition & - & - \\
\hline Yes & 68 & 22.7 \\
\hline No & 232 & 77.3 \\
\hline Total & 300 & 100.0 \\
\hline Diagnosed of respiratory diseases & - & - \\
\hline Yes & 112 & 37.3 \\
\hline No & 188 & 62.7 \\
\hline Total & 300 & 100.0 \\
\hline Able to go to work when not in good health? & - & - \\
\hline Yes & 66 & 25.0 \\
\hline No & 234 & 75.0 \\
\hline Total & 300 & 100.0 \\
\hline Education & - & - \\
\hline None & 54 & 18.0 \\
\hline Basic & 188 & 62.7 \\
\hline Secondary/Technical & 58 & 19.3 \\
\hline Total & 300 & 100.0 \\
\hline Marital status & - & - \\
\hline Never married & 38 & 12.7 \\
\hline Married & 172 & 57.3 \\
\hline Consensual union & 90 & 30.0 \\
\hline Total & 300 & 100.0 \\
\hline
\end{tabular}

Source: Field data, June 2017 


\subsection{Respondents' Knowledge and Practices Regarding Vehicle Emissions and Health}

Part of the objective of this study is to examine respondents' knowledge on vehicle emission, health and their practices towards averting or controlling respiratory infections associated with vehicle emissions. Respondents were asked if exposure to vehicle emissions has an effect on their health. Based on the sample, about 83 percent responded in the affirmative (Table 1). Further analysis of the data shows that the proportion of male respondents with knowledge of emissions and health were about 19 percentage points more than their female counterparts. There was also a significant difference between males and females with regards to vehicle emission health knowledge $(p=0.000)$. Of those who reported knowledge about the health risk associated with vehicle emissions, cough was the most reported respiratory symptom, followed by nausea/ running nose while wheezing and shortened breath was recorded the least reported symptoms of 3.2 and 1.6 percent respectively.

This study also collected data on reported symptoms of accompanier to know how respiratory symptoms vary between main respondents and accompaniers. In all, 40 accompaniers were identified. This refers to those who accompanied the main respondents to their place of work. In the case of accompaniers, wheeze recorded the highest reported respiratory symptom of 52.5 percent, followed by cough and chest pains (Figure 2). The differences in reported symptoms between main respondents and accompaniers was an indication of how differences in individual immune systems and genetic makeup influence the health status of people. However, because not much details of accompaniers were gathered it was difficult to establish relationships in prevalence rate of reported symptoms between main respondents and accompaniers.

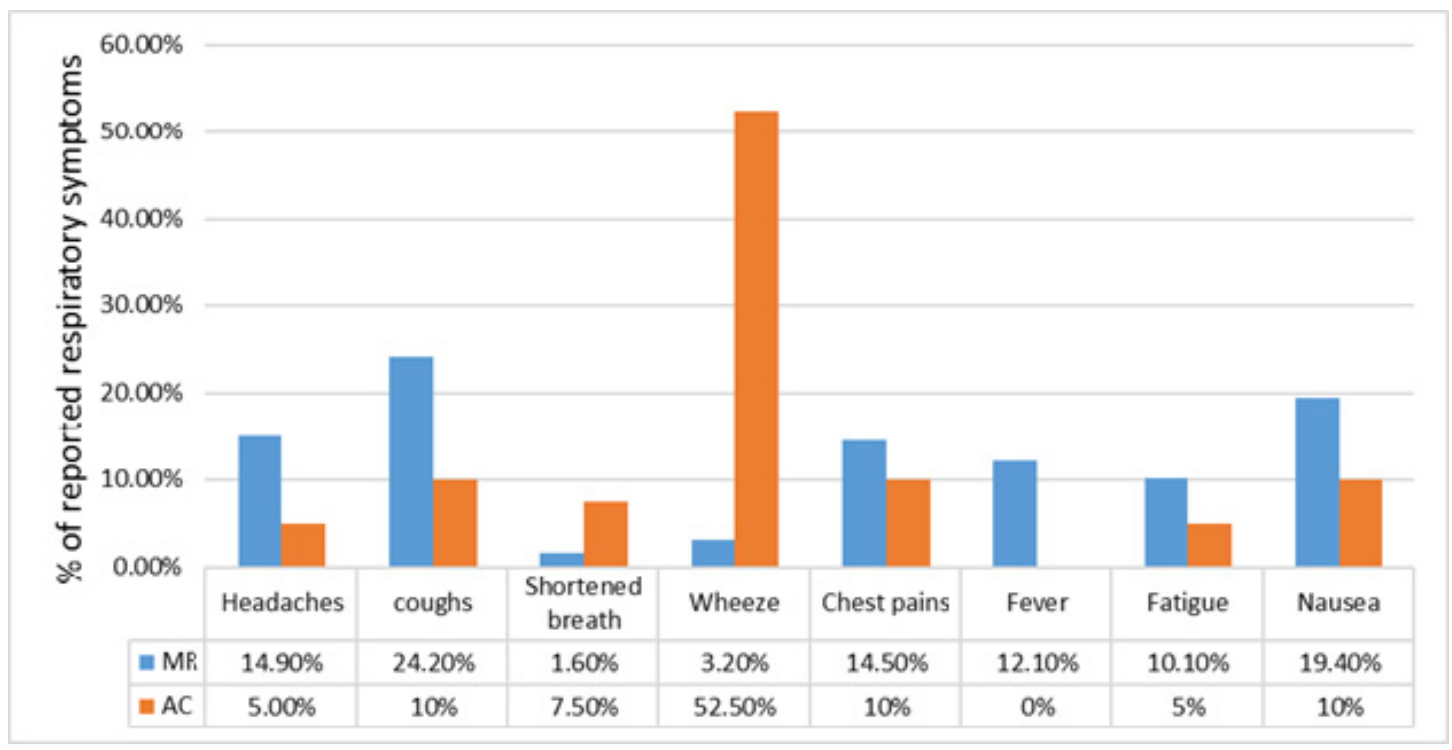

Figure 2. Reported cases of respiratory symptoms by respondents and accompaniers

Source: Field data, June 2017

Note: $\mathrm{MR}=$ main respondent; $\mathrm{AC}=\mathrm{Accompanier}$

It was also important to find out whether or not respondents considered relocating from their point of business since about 83 percent of them said they knew vehicle emissions has effect on their health. Based on the sample, 82.7 percent said they had no plans to relocate. Their reasons according to about 40 percent of the respondents, was because they could not afford another place of business while about 31 percent said they simply had nowhere else to go. The result suggests that factors other than knowledge about the health risk associated with vehicle emissions also compelled respondents to remain exposed to vehicle emissions

In terms of occupational risk, 68 percent of respondents mentioned harsh weather condition which includes extreme sunshine and rainfall while 18.3 percent said car fumes and heat. A small proportion (5\%) however said theft of goods and cash were the commonest risks associated with their job. The study found that the lack of urban space coupled with competition for market share as well as inability to afford convenient space where among major reasons why the majority of respondents were exposed to harsh weather conditions in their point of business. 


\subsection{Determinants of Risk Factors Associated with Respiratory Diseases}

To estimate the determinants of risk factors associated with respiratory diseases as the outcome of respondents' exposure to vehicle emissions, a marginal effect of logistic regression model was used to compute for the relative risk of demographic factors influencing respiratory diseases and the result are presented in Table 1. Studies (e.g. Nkosi et al 2015; Wen-Chao et al. (2007) indicate that as people age they become less immune to respiratory infections due to weakening immune system. Thus making age a significant risk factor for respiratory infection. This study therefore used both age and age squared as independent variables in the logit model to estimate their relative influence on risk of respiratory infection. Based on the sample, only age squared had a significant influence on risk of respiratory diseases. The educational level of people influences their knowledge of prevention of respiratory diseases. This study found bases on the sample that respondents with basic education qualification had about 15 percent significant probability of risk of respiratory diseases. In a study of how socioeconomic status of people relate with their exposure to respiratory disease such as chronic obstructive airways, Kanervisto et al., (2011) find based on a nationwide representative sample that basic education is an independent risk factor for chronic obstructive pulmonary diseases. It is therefore imperative to argue based on this study promoting the free secondary education agenda of Ghana and encouraging the youth to attain higher education is a necessary proactive measure in reducing future risk of exposure to respiratory disease among traders in general.

More importantly, distance from source of traffic emission had significant but different probability rate of influence on respiratory diseases. For instance, respondents sampled from 50 meters or less close to main roads had about 17 percent probability of exposure to respiratory diseases while those sampled from beyond 50 meters off the main road had about 8 percent probability of exposure. The finding agrees with other related studies (e.g. Robert and Howard 2012; Zuraimi et al. 2011) which found that distance from pollution source has varied but significant influence on the prevalence of respiratory diseases. For instance, Zuraimi et al. (2011) find that those who live an average distance of between 45 and 35 meters away from main traffic pollution source are three fold more exposed to respiratory diseases. The risk probability based on the study suggest that it is more importance for traders within the 50 meters radius to relocate to more distant location to lower their probable risk of exposure. The marginal effect of the years spent in the occupation at the designated point of business was found to have negative but significant probability of about 7 percent influence on risk of respiratory diseases exposure among the sample. This finding is opposite to the finding of Venn et al. (2001) who found positive significant influence between years spent close to traffic emission source and probability of exposure to respiratory diseases. Another significant risk factor of respiratory disease is the average working days per week by respondents.

Table 1. Marginal effect of risk factors associated with respiratory diseases

\begin{tabular}{lc}
\hline \multicolumn{1}{c}{ Variables } & Marginal Effect \\
\hline Age & $0.00351(0.07465)$ \\
Age squared & $0.08147 *(0.004710)$ \\
Gender $(G e n)$ & $-0.0252(0.0044)$ \\
Education $(E d u)$ & - \\
None & - \\
Basic & $0.1575^{* *}(0.0611)$ \\
Secondary/Technical & $0.0264(0.0831)$ \\
Distance from traffic pollution (Disp) & - \\
$\leq 50 \mathrm{~m}$ & $0.1723^{* *}(0.0914)$ \\
$>50 \mathrm{~m}$ & $0.0825^{*}(0.0023)$ \\
Years spent in occupation $($ YSD) & $-0.0664^{* *}(0.01655)$ \\
Average daily hours spent at work $(H S D)$ & $0.1346^{*}(0.0523)$ \\
Smoke & $0.0486(0.08731)$ \\
Observation & 300 \\
\hline Not: Sandard &
\end{tabular}

Note: Standard error in parenthesis; $* * \mathrm{P}<0.01 ; * \mathrm{P}<0.05$ 


\section{Discussion}

The general objective of the study was to assess vehicular emissions and its implication on health of traders in Madina. First, the study finds as high as 83 percent of respondents with knowledge about respiratory disease. Based on the literature, the high proportion of respondents with knowledge of vehicle emissions and health outcomes was expected to have same positive outcome on prevalence of respiratory diseases. However, this was not the case. Rather about 23 and 37 percent of the respondents indicated that they have been diagnosed for chronic and respiratory diseases respectively in the last six months. This implies that perhaps knowledge of exposure to vehicle emission and its consequential health outcomes does not necessarily transcend into reducing prevalence of respiratory diseases among the exposed population.

In terms of preventive practices, some limiting factors including inability to afford a different location, no other place to move to and ready market at current place of business were mentioned as reasons why respondents were stacked at their designated place of business regardless of their exposure to vehicle emissions. This finding suggest a possible expansion of the physical space for market in the cities where traders could have available space to carry out their activity distant from the traffic related emissions. Also, knowledge of what constitute air pollution in the city was examined. Although the majority of respondents identified car fumes and use of generators in urban spaces by shop owners as major contributors to air pollution and risk factors associated with their jobs, about 68 percent of them said they often do nothing to protect themselves from air pollution. This possibly may also account for reasons why despite high knowledge about respiratory disease and its prevention, reported symptoms of chronic respiratory disease among respondents was found to be prevalent among 22.6 percent of total respondents.

Findings on emissions and self-reported health and its effect also show relatively complex outcomes. For instance, both male and female respondents reported same but different prevalence of respiratory disease symptoms. While female respondents recorded the highest prevalence of influenza, the majority of male respondents reported pneumonia and bronchitis compared with the female respondents. Also, the majority of respondents (75\%) said they were unable to go work when ill and that affected their income and goods. It was also found that the majority of respondents who reported ill in the last six months depended on their household income to finance their health expenditure. However, further analysis revealed that in proportionate terms, more female than male respondents financed their health expenditure using household income. Interestingly, reported cases of respiratory disease symptoms was relatively different between main respondents and their accompaniers. In the case of accompaniers, wheeze was identified as the prevalent symptom while cough, headache, and nausea was dominant among main respondents. However, lack of sufficient data and focus of the study did not allow for further probing to find reasons for the differences in the prevalence of reported respiratory symptoms.

Risk factors associated with respiratory diseases were estimated using marginal effects of logit regression model. Based on the sample estimation, the model identified both exogenous and endogenous risk factors including basic education, age squared, years spent in the occupation, working days per week, and distance from pollution source as significant factors influencing respiratory diseases among respondents.

\section{Conclusion}

The rise of respiratory diseases remains a worrying development issue across the globe, especially with growing evidence mortality and morbidity effects of road traffic emissions in developing regions of the world including Ghana. This study has examined the knowledge and practices with regards to emissions and respiratory diseases and symptoms among traders in Madina who are exposed to traffic emissions. It has shown based on self-reported health impacts of vehicle emission that those exposed to vehicle emission actually faces diverse health challenges including poor visibility, difficulty in breathing, nausea among others. The effect of distance from traffic pollution source on health outcomes was also investigated. This study has found that distance from emission vehicle emission source reduces the health outcomes and the distribution in terms of self-reported health by distance was significantly different. More importantly, although preventive knowledge is key to reducing prevalence of respiratory disease, the findings suggest that this does not happen in all cases.

It is however important to argue that lack of data on exact concentration of different levels of chemicals in the emitted gas from vehicles could not allow for any rigorous testing of each gaseous chemical contributed to the prevalence and diagnosis of respiratory diseases and symptoms as indicated in the conceptual framework by the Health Research Institute (2010). Such analysis could have helped determined both crude and adjust odd ratios of how each chemical constituent influence the prevalence of respiratory diseases and symptoms. It could also have helped prescribed exact measures for reducing difference levels of chemicals emitted by vehicles as part of measures to reduce emission related health implications. A further limitation noted is the fact that there are other 
sources of air pollution such as the method of cooking at home which were not controlled for in the study.

\section{Recommendations}

By adopting good preventive practices such as avoiding prolonged exposure to traffic emissions and also the wearing of personal protective equipment there will be a significant reduction of respiratory diseases. Therefore, the Environmental Protection Agency (EPA) of Ghana should make deliberate effort to increase air pollution surveillance stations across the country to monitor different levels of gaseous concentration to help come out with appropriate measures to reducing emissions in urban space. Such data could facilitate more rigorous research and findings with regards to tracking progress on risk of air pollution reduction and its consequential health outcomes. Based on the dimensions of the impact in terms self-reported health associated with vehicle emissions, it is recommended that the city authorities must take pragmatic steps to relocate traders beyond a distance of 100 meters or more from the major roads where emissions are quite severe. Prospective traders and those already in their designated locations should be educated on the health implications of their exposure to air pollution and potential impact on their livelihoods.

\section{References}

Alim, A. M., Sarker, M. A. B., Selim, S., Karim, M. R., Yoshida, Y., \& Hamajima, N. (2014). Respiratory involvements among women exposed to the smoke of traditional biomass fuel and gas fuel in a district of Bangladesh. Environ Health Prev Med, 19, 126-134. https://doi.org/10.1007/s12199-013-0364-4

Alirol, E., Getaz, L., Stoll, B., Chappuis, F., \& Loutan, L. (2010). Urbanisation and infectious diseases in a globalised world. Lancet Infect Dis, (10), 131-41.

Amugsi, D. A., Aborigo, R. A., Oduro, A. R., Asoala, V., Awine, T., \& Amenga-Etego, L. (2015). Socio-demographic and environmental determinants of infectious disease morbidity in children under 5 years in Ghana. Glob Health Action 2015, 8: 29349. http://dx.doi.org/10.3402/gha.v8.29349

Apte, J. S., Bombrun, E., Marshall, J. D., \& Nazaroff, W. W. (2012). Global Intra-urban Intake Fractions for Primary Air Pollutants from Vehicles and Other Distributed Sources. Environmental Science and Technology, 46(6), 3415-3423. https://doi.org/10.1021/es204021h

Bell, M. L. et al. (2006). The avoidable health effects of air pollution in three Latin American cities: Santiago, Sao Paulo, and Mexico City. Environmental Research, 100, 431-440. https://doi.org/10.1016/j.envres.2005.08.002

Beydoun, M., \& Guldmann, J. M. (2006). Vehicle characteristics and emissions: logit and regression analyses of inspection and maintenance data from Massachusetts, Maryland, and Illinois. Transportation Research Part D 11, 59-76. https://doi.org/10.1016/j.trd.2005.09.003

Bloom, D. E., Canning, D., \& Sevilla, J. (2004). The Effect of Health on Economic Growth: A Production Function Approach. World Development, (32), 1-13. https://doi.org/10.1016/j.worlddev.2003.07.002

Brauer, M. et al. (2002). Air Pollution from Traffic and the Development of Respiratory Infections and Asthmatic and Allergic Symptoms in Children. Am J Respir Crit Care Med, 166, 1092-1098. https://doi.org/10.1164/rccm.200108-007OC

Cesaroni, G., Forastiere, F., Stafoggia, M., Andersen, Z. J., Badaloni, C., Beelen, R., ... Peters, A. (2014). Long term exposure to ambient air pollution and incidence of acute coronary events: prospective cohort study and meta-analysis in 11 European cohorts from the ESCAPE Project Br. Med. J., 348, p. f7412. https://doi.org/10.1136/bmj.f7412

Cetinkaya, F., Gu“lmez, I., Aydin, T., Oztürk, Y., Ozesmi, M., \& Demir, R. (2000). Prevalence of chronic bronchitis and associated risk factors in a rural area of Kayseri, Central Anatolia, Turkey. Monaldi ArchChest Dis., (55), 189-93.

Chauhan, A. J., \& Johnson, S. L. (2003). Air pollution and infection in respiratory illness. British Medical Bulletin, 68, 95-112. https://doi.org/10.1093/bmb/ldg022

Chen, Y., Williams, E., \& Kirk, M. (2014). Risk Factors for Acute Respiratory Infection in the Australian Community. PLoS ONE, 9(7), e101440. https://doi.org/10.1371/journal.pone.0101440

Cifuentes, L. A., Krupnick, A. J., O'Ryan, R., \& Toman, M. A. (2005). Urban air quality and human health in Latin America and the Caribbean. Retrieved from http://www.cepal.org/ilpes/noticias/paginas/5/22145/Cifuentes\%20et\%20al.\%20reporte\%20-\%20IADB.pdf

Cohen, A. et al. (2004). Urban Air Pollution. In M. Ezzati, A. D. Lopez, A. Rogers, \& C. J. L. Murray (Eds.), 
Comparative Quantification of Health Risks (Vol. 2, p. 1353). Geneva: World Health Organization.

Cohen, J. E. (2010). Beyond population: everyone counts in development. Retrieved from http://www.cgdev.org/files/1424318_file_Cohen_BeyondPopulation_FINAL.pdf

Creswell, J. W., \& Clark, P. V. L. (2007). Designing and conducting mixed methods research. Thousand Oaks, CA: Sage Publications.

Deloitte-Africa. (2016). Navigating the African Automotive Sector: Ethiopia, Kenya and Nigeria. Retrieved from https://www2.deloitte.com/content/dam/Deloitte/za/Documents/manufacturing/ZA_Deloitte-Africa-automot ive-insights-Ethiopia-Kenya-Nigeria-Apr16.pdf

Dimitriou, A., \& Christidou, V. (2011). Causes and Consequences of Air Pollution and Environmental Injustice as Critical Issues for Science and Environmental Education. In Khallaf, M. (Ed.), The Impact of Air Pollutionon Health, Economy, Environment and Agricultural Sources. https://doi.org/10.5772/17654

Environment Protection Agency. (2015). Ghana's Third Communication Report to the UNFCCC, 2015 Climate Change Report.

European Environment Agency (EEA). (2006). Air pollution at street level in European cities. Copenhagen: EEA.

Ganesh, K. S., Anindo, M., Veera, K., Bijay, N. N., Kalaiselvi, S., \& Karthik, B. (2015). Prevalence of acute respiratory infection among under-five children in urban and rural areas of Puducherry, India. Journal of Natural Science, Biology and Medicine, 6(1), 3-6. https://doi.org/10.4103/0976-9668.149069

Ghana Statistical Service. (2014). 2010 Population and Housing Census District Analytical Report for La Nkwantanang Madina Municipality. Accra: Ghana Statistical Service.

Health Effects Institute. (2010). Traffic-related air pollution: A critical review of the literature on emissions, exposure and health effects. 2010 Special Report \# 17. Retrieved from https://www.healtheffects.org/system/files/SR17Traffic\%20Review.pdf

Héroux, M.-E., Anderson, H. R., Atkinson, R., Brunekreef, B., Cohen, A., Forastiere, F., ... Walton, H. (2015). Quantifying the health impacts of ambient air pollutants: recommendations of a WHO/Europe project. International Journal of Public Health, 60(5), 619-627. http://doi.org/10.1007/s00038-015-0690-y

Hwang, B. F., Lee, Y. L., Lin, Y. C., Jaakkola, J. J., \& Guo, Y. L. (2005). Traffic related air pollution as a determinant of asthma among Taiwanese school children. Thorax, 60, 467-473. https://doi.org/10.1136/thx.2004.033977

International Energy Agency. (2016). Energy and Air Pollution. World Energy Outlook, Special Report. Retrieved from www.se4all.org/sites/default/files/WEO-Energy-Air-Pollution.pdf

Kampa, M., \& Castanas, E. (2008). Human health effects of air pollution. Environmental Pollution, 151, 362-367. https://doi.org/10.1016/j.envpol.2007.06.012

Kanervisto, M., Vasankari, T., Laitinen, T., Heliövaara, M., Jousilahti, P., \& Saarelainen, S. L. (2011). Socioeconomic status is associated with chronic obstructive airway diseases. Respir Med., 105(8), 1140-6. https://doi.org/10.1016/j.rmed.2011.03.008

Khreis, H., Kelly, C., Tate, J., Parslow, R., Lucas, K., \& Nieuwenhuijsen, M. J. (2016). exposure to traffic-related air pollution and risk of development of childhood asthma: a systematic review and meta-analysis Environ. Int.

Kumekpor, T. K. B. (2002). Research Methods and Techniques of Social Research. Accra: Sun Life Publication.

Kurt, O. K., Zhang, J., \& Pinkerton, K. E. (2016). Pulmonary Health Effects of Air Pollution. Current Opinion in Pulmonary Medicine, 22(2), 138-143. http://doi.org/10.1097/MCP.0000000000000248

Liao, X. et al. (2015). Residents' perception of air quality, pollution sources, and air pollution control in Nanchang, China. Atmospheric pollution research, 6(5), 835-841. https://doi.org/10.5094/APR.2015.092

MacIntyre, E. A., Gehring, U., Mölter, A., Fuertes, E., Klümper, C., Krämer, U., ... Heinrich, J. (2014). Air Pollution and Respiratory Infections during Early Childhood: An Analysis of 10 European Birth Cohorts within the ESCAPE Project. Environmental Health Perspectives, 122(1), 107-113. http://doi.org/10.1289/ehp.1306755

Neuman, W. L. (2010). Social Research Methods: Qualitative and Quantitative Research Approaches (4th ed.). USA: University of Wisconsin Press. 
Nkosi, V., Wichmann, J., \& Voyi, K. (2015). Chronic respiratory disease among the elderly in South Africa: any association with proximity to mine dumps? Environmental Health, 14, 33. https://doi.org/10.1186/s12940-015-0018-7

Odame, S. K. (2015). Police-Driver Interaction and Traffic Law Enforcement in Madina. Unpublished Master Thesis Submitted to the University of Ghana.

Oguntoke, O., \& Yussuf, A. S. (2008). Air Pollution arising from Vehicular Emissions and the associated Human Health Problems in Abeokuta Metropolis, Nigeria. ASSET Series, 119-132.

Omole, D. O., \& Ndambuki, J. M. (2014). Sustainable Living in Africa: Case of Water, Sanitation, Air Pollution and Energy. Sustainability, 6, 5187-5202. https://doi.org/10.3390/su6085187

Oosterlee, A., Drijver, M., Lebret, E., \& Brunekreef, B. (1996). Chronic respiratory symptoms of children and adults living along streets with high traffic density. Occup Environ Med., (53), 241-24. https://doi.org/10.1136/oem.53.4.241

Pandian, S., Gokhale, S., \& Ghoshal, A. K. (2008). Evaluating effects of traffic and vehicle characteristics on vehicular emissions near traffic intersections. Transportation Research Part D 14 (2009) 180-196.

Qian, X., et al. (2016). Knowledge and perceptions of air pollution in Ningbo, China. BMC Public Health, 16(1138), 1-7. https://doi.org/10.1186/s12889-016-3788-0

Ribeiro, H., Regina, M., \& Cardoso, A. (2003). Air pollution and children's health in Sao Paulo (1986-1998). Social Science \& Medicine, 57, 2013-2022. https://doi.org/10.1016/S0277-9536(03)00068-6

Robert J. L., \& Howard, M. K. (2012). Respiratory Health Effects of Air Pollution: Update on Biomass Smoke and Traffic Pollution. Journal of Allergy Clinical Immunology, 129(1), 3-13. https://doi.org/10.1016/j.jaci.2011.11.021

Rohde, R. A., \& Muller, R. A. (2015). Air Pollution in China: Mapping of Concentrations and Sources. PLoS ONE, 10(8). https://doi.org/10.1371/journal.pone.0135749

Schwartz, J. (2004). The effects of particulate air pollution on daily deaths: a multi-city case-crossover analysis. Occup Environ Med., 61, 956-961. https://doi.org/10.1136/oem.2003.008250

Selvaraj, K., Chinnakali, P., Majumdar, A., \& Krishnan, I. S. (2014). Acute respiratory infections among under-5 children in India: A situational analysis. Journal of Nat. Sci. Biol Med., 5(1), 15-20. https://doi.org/10.4103/0976-9668.127275

Semenza, J. C., Rockllov, J., Penttinen, P., \& Lindgren, E. (2016). Observed and projected drivers of emerging infectious diseases in Europe. Ann. N.Y. Acad. Sci., 1382, 73-83. https://doi.org/10.1111/nyas.13132

Seon-Ju. Y., Changwoo, S., Kyung-Duk, M., Hwan-Cheol, K., Jong-HanLeem, Ho Jang, K., ... Sun-Young, K. (2017). Association between Exposure to Traffic-Related Air Pollution and Prevalence of Allergic Diseases in Children, Seoul, Korea, BioMed Research International Volume 2017.

Tetteh-Addison, E. (2012). Vehicle population and international trend. Retrieved from http://www.unep.org/transport/pcfv/PDF/Ghana_2012/VehiclePopulation Trends.pdf

UNEP. (2014). Air Pollution: World's Worst Environmental Health Risk. UNEP Year Book 2014 emerging issues update. New York: UNEP Publications.

US Environmental Protection Agency. (2009). Exposure Factors Handbook: 2009. Washington, DC: US-EPA.

Venn, A. J., Lewis, S. A., Cooper, M., Hubbard, R., \& Britton, J. (2001). Living near a main road and the risk of wheezing illness in children. Am $J$ RespirCrit Care Med., (164), 2177-2180. https://doi.org/10.1164/ajrccm.164.12.2106126

Venn, A., Yemaneberhan, H., Lewis, S., Parry, E., \& Britton, J. (2005). Proximity of the home to roads and the risk of wheeze in an Ethiopian population. Occup Environ Med, 62, 376-380. https://doi.org/10.1136/oem.2004.017228

Vichit-Vadakan, N., Vajanapoom, N., \& Ostro, B. (2008). The Public Health and Air Pollution in Asia (PAPA) Project: Estimating the Mortality Effects of Particulate Matter in Bangkok, Thailand. Environmental Health Perspectives, 116(9), 1179-1182. https://doi.org/10.1289/ehp.10849

Wen-Chao, H. et al. (2007). Air pollution, weather, and associated risk factors related to asthma prevalence and attack rate. Environmental Research, 104, 402-409. https://doi.org/10.1016/j.envres.2007.01.007 
WHO. (2000). Air quality guidelines for Europe (2nd ed.). Copenhagen: WHO regional publications No. 91.

WHO. (2002). Health and sustainable development. Retrieved from http://www.who.int/mediacentr e/events/HSD_Plaq_02.2_Gb_def1.pdf

WHO. (2011). Noncommunicable diseases country profiles 2011. France: World Health Organization.

WHO. (2014). Noncommunicable diseases country profiles 2011. Geneva: World Health Organization.

World Health Organization. (2015). Ghana: WHO Statistical Profile. Retrieved from https://www.medbox.org/gh-nhp-statistics/ghana-who-statistical-profile/preview?

Zachariadis, T., Ntziachristos, L., \& Samaras, Z. (2001). The effect of age and technological change on motor vehicle emissions. Transportation Research Part D., (6), 221-227. https://doi.org/10.1016/S1361-9209(00)00025-0

Zuraimi, M. S., Tham, K.-W., Chew, F.-T., Ooi, P.-L., \& Koh, D. (2011). Home air-conditioning, traffic exposure, and asthma and allergic symptoms among preschool children. Ped Allergy Immunology, 22(1pt2), e112-e118. https://doi.org/10.1111/j.1399-3038.2010.00992.x

\section{Copyrights}

Copyright for this article is retained by the author(s), with first publication rights granted to the journal.

This is an open-access article distributed under the terms and conditions of the Creative Commons Attribution license (http://creativecommons.org/licenses/by/4.0/). 